\title{
Flexible Evaluation of BPMS User Based on AHP
}

\author{
Jianing Wang", Wukui Wang and Jianming Mei
}

School of Economics \& Management, Beijing Forestry University, Beijing, 100083, China

\begin{abstract}
Business process management is an important idea and management method of enterprise management. More and more enterprises are paying attention to the management process. As a combination of enterprise informatization and business process management, the application of business process management software (BPMS) has attracted a lot of attention. In the face of various BPMSs, how to choose the very BPMS becomes a problem for enterprises. BPMS evaluation is a complex multi-dimension decision, which can be made from different visual angles and dimensions. AHP is very effective in solving this problem. This paper, from user's perspective, puts forward the evaluation index system of user flexibility using the established evaluation model based on AHP method, scored by experts to determine the weight of each index. Finally, the flexible evaluation of the two Chinese BPMS softwares has been carried out.
\end{abstract}

Keywords: AHP, business process management software, evaluation, flexible.

\section{INTRODUCTION}

With the popularity of information technology and improvement of management, enterprises need to implement information systems adapting to their own needs in order to realize effective management. From the perspective of process management which takes into consideration the enterprise business process management theory, many companies launched kinds of information systems to support their business process management, such as Business Process Management System (BPMS) [1, 2]. How to choose BPMS is mainly carried out from three angles, i.e. the characteristics of software itself, credibility and flexibility. The core advantage of BPMS is reflected in the system's or software's flexibility for complicated business support, so the evaluation should be focused mainly on BPMS flexibility [3, 4]. In this paper, based on the user's viewpoint of the system's flexibility, we studied BPMS to find a proper flexible system support when using BPMS that some users need to be provided. We presented the measure model combining the existing software metric model with BPMS metrics model and proposed a flexibility evaluation system. Finally, we tested this model based on expert's marking to determine the weight distribution by comparing two BPMS models in the People's Republic of China.

\section{THE RELATED RESEARCH}

\subsection{Software Quality Metrics Model}

In the field of software engineering, many scholars have carried on software quality evaluation work, and have put forward some software quality metrics models, including McCall model, Boehm model, ISO model, etc. Jim McCall proposed software quality model from 3 perspectives,

*Address correspondence to this author at the School of Economics and Management, Beijing Forestry University, Haidian, Beijing, 100083, China; Tel: +86 13021231441; E-mail: astjw4545@163.com product revision, product transition and product operations, to define and identify the quality of software products. The McCall model is a hierarchical metric model including three layers, the software quality factors, standards and measures. McCall defined 11 elements to describe the quality of the software, which are correctness, reliability, efficiency, integrity, usability, maintainability, testability, flexibility, portability, reusability and interoperability. Because it is not easy to judge a software's quality based on measuring the 11 elements, McCall also defined 23 criteria including traceability, completeness, consistency, accuracy, error tolerance and others.

B.W. Boehm put forward the concept of quantitative evaluation of software quality. He tried to quantize the software quality through a series of attribute indicators. The Boehm model is similar to the McCall. It consists of the top, middle, and original properties, and is also a hierarchical model. The top property concerns As-is utility, maintainability and portability; while the middle property contains seven quality factors, including portability, reliability, efficiency, usability, testability, understandability and flexibility. On the basis of McCall model and Boehm model, the International Standardization Organization(ISO) adds the functional requirements into the evaluation, puts forward the ISO9126 software quality metric model, and points out six major quality characteristics of a software: i.e. functionality, reliability, usability, efficiency, maintainability and portability.

These three kinds of models all are software quality management models, sharing many factors among them. All of them start from different elements of quality characteristics, measuring the indices in various layers according to different metrics, and then obtain the evaluation of whole software or system. These models can provide the basis and method for BPMS evaluation. But the three models have been designed from the perspective of a system. The heart of BPMS is process management, and business people and managers are the key users of BPMS, so the evaluation should not start from 
the viewpoint of system only, but should also consider business activities and related users.

\subsection{Workflow Patterns}

Workflow Patterns is a research activity beginning in Technische Universiteit Eindhoven and Queensland University of Technology at 1999. Its purpose is to provide a conceptual basis in the workflow field. Work flow Patterns tests workflow language and business process modeling language from 4 aspects as follows: the control flow, data, resources and exception handling $[5,6]$. The test results can be used to analyze whether the process of language and the information system fits a particular business activity.

Control flow describes the business activities and the execution sequence between different staff's activities, such as sequential, parallel and choice. Resource is defined as the ability of some business entity, which can either be a person, or any other non-human unit. Data model provides a description about the performance of the data in a workflow. Exception handling model provides a classification framework of exception handling when information system recognizes the process. Workflow model has been used to test the suitability of a variety of standard languages (BPEL, BPMN, XPDL, UML etc.) and commercial softwares (Staffware, WebSphere MQ Workflow, Flower etc.). Many software companies, such as IBM, Oracle, COSA etc. also use the workflow model to study their products; Petia Wohed, Nick Russell analyzed and evaluated three open-source BPM softwares (jBPM, OpenWFE, Enhydra Shark) based on the workflow patterns.

\subsection{BPMS Evaluation Based on BSC}

Balanced scorecard measures the performance from the financial, internal users, business activities, learning and growth aspects. As BSC is the most commonly used method of performance appraisal, we consider connecting each dimension in BSC with BPMS to establish an evaluation system of BPMS based on BSC [7].

Process cost and budget can be used as indicators in the financial dimension. Agility, user management and satisfaction can be used as indicators in the user dimension. Objectives and potential can be used as indicators in the learning and growth perspective. For the internal business process perspective, we choose the monitoring, management, visualization and complexity as evaluation indices.

BSC based evaluation system makes a combination of BPMS and actual business, instead of just examining the functionality of a system. It looks at BPMS at a higher level, which is concerned with detailed business and management, which is needed by the enterprises when studying BPMS.

All software quality measurement models, workflow model and BSC based BPMS evaluation system can be used to evaluate a BPMS. But, the former two focus on the perspective of information system, while the latter measures the BPMS from the perspective of integration of business and systems. Considering BPMS is the bridge linking users and businesses, it is necessary to view BPMS from both user and system aspects which means that they should not be separated.

\section{THE EVALUATION SYSTEM BASED ON USER FLEXIBILITY}

The BPMS users can make all kinds of operations to configure, by adjusting the software to adapt to the changes when there are new business requirements or changes in the environment.

In the process of user's adjustment, the adaptability exhibited by BPMS is determined by the IS flexibility. We define the user feeling degree of IS flexibility during this period as user flexibility. If the user thinks it is easy and convenient to make changes then we can conclude that the user flexibility is strong.

\subsection{Functional Dimensions}

Functional dimension reflects the ability of how a system can meet the requirements of different users. In this dimension, we mainly inspect the flexibility-to-use. Flexibility-to-use means the range provided by a system when it needs not to change while changes occur. If the range is wide, user feels the system is more flexible, then we can say the user flexibility is strong.

Enterprise business process management includes the process description, process optimization, process informatization, process real-time monitoring, and process performance evaluation. BPMS should be able to achieve these functions; the higher the satisfaction degree of BPMS on these aspects, the higher this aspect of flexibility is. We can consider the functional flexibility of BPMS from the 6 aspects.

Ability to design a process mainly refers to the ability of business people to describe and design business processes by BPMS. Process designing is divided into two parts, modeling capacity and design capability. There are many ways of process direction. When designing is based on various approaches of complicated processes, BPMS covering and supporting more aspects will provide users with greater help.

Process execution consists mainly of startup, task transfer and the end. The ability of execution is defined as task distribution and automation ability. So, when the task is transferred to different participating users, their efficiency is very important, which underlies the user's experience. Although the user is the task executor, yet process task is automatically run in the system. So, task arrival notification, completion notification, processing time notification are essential as they may impact the efficiency of tasks implementation.

Process optimization is a key to business process. We take account of the optimization ability provided by BPMS. It is based on the simplicity of process report and improvement as well as optimization range.

The users are the participants of the process, and also the main object of the organization management. Business process management has exceeded to the limit of functional management. Therefore, the administration of people has become one of the new difficulties in the management.

Whether the ordinary users in a process or the managers controlling the whole business, it is required to monitor and manage the business process. The users view their own work 
status and employee's situation by tracking the process. BPMS should have the ability to provide views of different granularities to meet various business needs.

Management or performance appraisal departments need to work on the staff performance appraisal. It is hoped that BPMS has a variety of forms and angles to meet the performance appraisal requirement. Users will feel a higher flexibility in the process if they are able to get whatever KPIs they want. The performance indices of BPMS contain the sufficient quantity of KPIs, present formats and BI applications, which can reflect the user flexibility.

\subsection{Portability and Maintainability}

Portability is used to measure whether the system can be easily deployed to different operating environments. Maintainability is reflecting the effort required when system are making adjustment to match changes. So, consider flexibility from the perspective of portability and maintainability, it means considering the flexibility-to-change which means the degree of alter, update and extension.

\subsection{Usability and Reliability}

Usability reflects the effort paid to while operation BPMS. Reliability refers to the ability of the system stability under certain conditions. On one hand, BPMS should be able to accurately describe the user's activity, and try to meet the user's operating habits, otherwise it is very error-prone. On the other hand, if the error occurs, BPMS should have a good recovery ability. For users, using BPMS is a simple and small task, as it is simple to operate BPMS, and can improve the safety, which means user flexibility for BPMS is high and strong.

\section{AHP MODEL}

\subsection{Create the AHP Model}

AHP is a systemic method of analyzing multi-target, multi-criteria and multi-factor problem. It is proposed by a USA mathematician Saaty in 1970s. It took the research object as a system, making decisions according to the approach of resolving, comparing, judging, and synthesizing. In the evaluation system of BPMS based on user flexibility, the users flexibility is divided into 3 dimensions, reflected by 12 detailed indicators, which is in line with the thought of AHP.

\subsection{Constructing Judgment Matrix}

It can be seen in the Fig. (1). First level target (B1-B3) and second level index layer (C1-C12) will affect the user flexibility (A). In order to study the influence of various indicators for goals, we make pairwise comparison to get the importance degree of each index.

\subsection{Measurement and Data Collection}

After the establishment of the AHP level and the judgment matrix which is available in Table $\mathbf{1}$, carry out the measurement and data collection. It needs to find a group of experts to score the indices with different weight.
We contacted four experts for their valuable suggestions for this study. One of them is a senior software engineer. Two of them are project managers from two famous consulting firms. The last expert is an experienced senior implementation consultant. Each of them gets a card of introduction for the model and a table needs to input the weight according to their knowledge and understanding.

\subsection{Determine the Weight}

After normalization processing, we got the weight in all the matrices. In additional, The CR values are less than 0.1 , which is considered to pass the consistency check. Table 2 shows these results.

Table 1. Judgment Matrix.

\begin{tabular}{|c|c|c|c|c|}
\hline $\mathbf{A}$ & $\mathbf{B 1}$ & $\mathbf{B 2}$ & $\mathbf{B 3}$ & Weight \\
\hline \hline $\mathrm{B} 1$ & 1.000 & 1.897 & 1.152 & 0.403 \\
\hline $\mathrm{B} 2$ & 0.527 & 1.000 & 0.357 & 0.179 \\
\hline $\mathrm{B} 3$ & 0.868 & 2.801 & 1.000 & 0.418 \\
\hline & & & & $\mathrm{CR}=0.027$ \\
\hline B1 & $\mathbf{C} 1$ & $\mathbf{C}$ & $\mathbf{C 3}$ & weight \\
\hline \hline $\mathrm{C} 1$ & 1.000 & 2.431 & 0.874 & 0.402 \\
\hline $\mathrm{C} 2$ & 0.411 & 1.000 & 0.493 & 0.184 \\
\hline $\mathrm{C} 3$ & 1.144 & 2.028 & 1.000 & 0.414 \\
\hline & & & & $\mathrm{CR}=0.010$ \\
\hline
\end{tabular}

\begin{tabular}{|c|c|c|c|c|c|c|c|}
\hline B2 & C4 & C5 & C6 & C7 & C8 & C9 & $\begin{array}{c}\text { weig } \\
\text { ht }\end{array}$ \\
\hline \hline C4 & 1.000 & 1.817 & 1.587 & 1.587 & 1.260 & 3.557 & 0.260 \\
\hline C5 & 0.550 & 1.000 & 1.587 & 1.587 & 1.260 & 1.817 & 0.190 \\
\hline C6 & 0.630 & 0.630 & 1.000 & 1.587 & 1.587 & 1.587 & 0.170 \\
\hline C7 & 0.630 & 0.630 & 0.630 & 1.000 & 1.817 & 1.442 & 0.149 \\
\hline C8 & 0.794 & 0.794 & 0.630 & 0.550 & 1.000 & 1.817 & 0.137 \\
\hline C9 & 0.382 & 0.550 & 0.630 & 0.693 & 0.550 & 1.000 & 0.094 \\
\hline & & & & & & & $\begin{array}{c}\mathrm{CR}=0 \\
.035\end{array}$ \\
\hline
\end{tabular}

\begin{tabular}{|c|c|c|c|c|}
\hline B3 & C10 & C11 & C12 & Weight \\
\hline \hline $\mathrm{C} 10$ & 1.000 & 1.000 & 1.357 & 0.361 \\
\hline $\mathrm{C} 11$ & 1.000 & 1.000 & 1.817 & 0.398 \\
\hline $\mathrm{C} 12$ & 0.737 & 0.550 & 1.000 & 0.242 \\
\hline & & & & $\mathrm{CR}=0.008$ \\
\hline
\end{tabular}




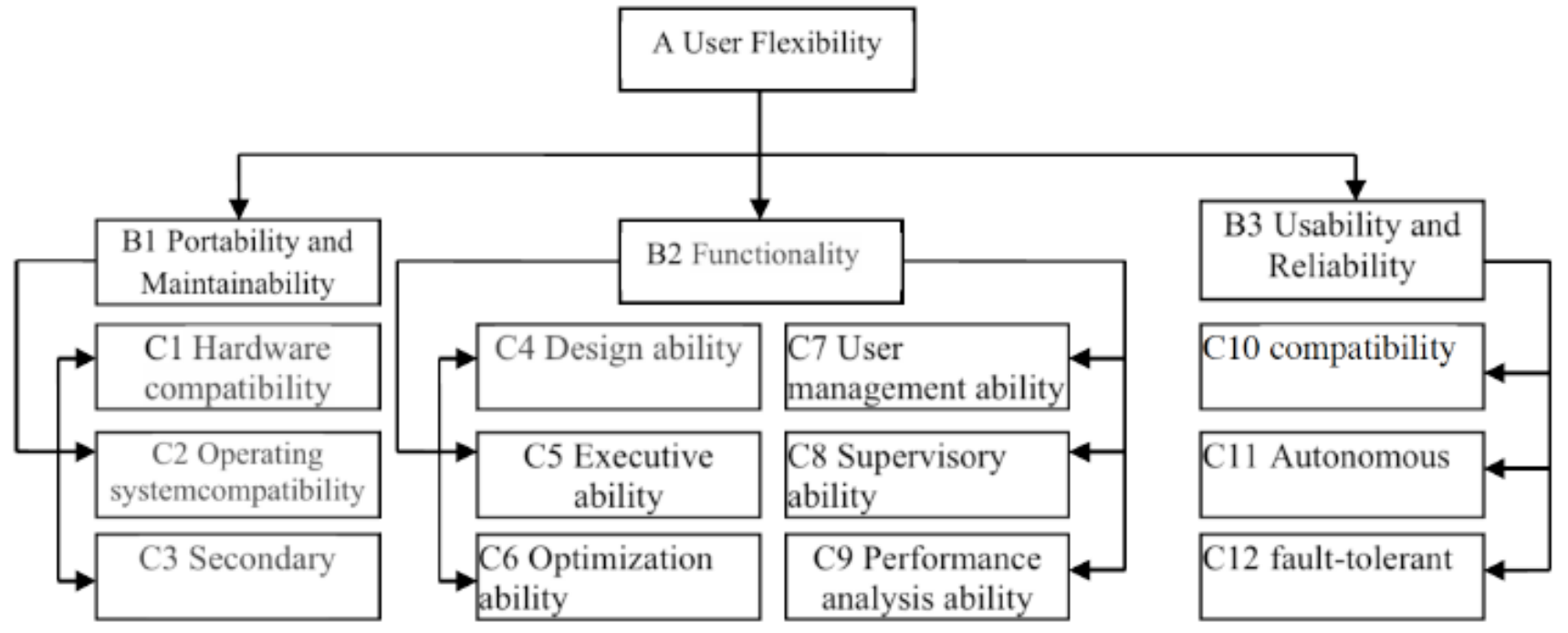

Fig. (1). Flexible evaluation model of BPMS user based on AHP.

Table 2. Global Weight.

\begin{tabular}{|c|c|c|c|c|}
\hline First index & Part weight & First index & Part weight & Global Weight \\
\hline \multirow[t]{3}{*}{ B1 } & 0.403 & $\mathrm{C} 1$ & 0.402 & 0.162 \\
\hline & & $\mathrm{C} 2$ & 0.184 & 0.074 \\
\hline & & $\mathrm{C} 3$ & 0.414 & 0.167 \\
\hline \multirow[t]{6}{*}{ B2 } & 0.179 & $\mathrm{C} 4$ & 0.260 & 0.047 \\
\hline & & $\mathrm{C} 5$ & 0.190 & 0.034 \\
\hline & & C6 & 0.170 & 0.030 \\
\hline & & $\mathrm{C} 7$ & 0.149 & 0.027 \\
\hline & & $\mathrm{C} 8$ & 0.137 & 0.025 \\
\hline & & C9 & 0.094 & 0.017 \\
\hline \multirow[t]{4}{*}{ B3 } & 0.418 & $\mathrm{C} 10$ & 0.361 & 0.151 \\
\hline & & $\mathrm{C} 11$ & 0.398 & 0.166 \\
\hline & & $\mathrm{C} 12$ & 0.242 & 0.101 \\
\hline & & & & Total $=1.000$ \\
\hline
\end{tabular}


Table 3. BPMS evaluation Result

\begin{tabular}{|c|c|c|c|c|c|}
\hline \multirow{2}{*}{$\begin{array}{c}\text { First index } \\
\text { Second index }\end{array}$} & \multirow{2}{*}{ Global Weight } & \multicolumn{2}{|c|}{ A system } & \multicolumn{2}{|c|}{ B system } \\
\hline & & score & $\times \mathbf{G W}$ & score & $\times \mathbf{G W}$ \\
\hline \multicolumn{6}{|l|}{ B1 } \\
\hline $\mathrm{C} 1$ & 0.162 & 5 & 0.810 & 5 & 0.810 \\
\hline $\mathrm{C} 3$ & 0.167 & 20 & 3.338 & 10 & 1.669 \\
\hline \multicolumn{6}{|l|}{ B2 } \\
\hline $\mathrm{C} 4$ & 0.047 & 29 & 1.352 & 18 & 0.839 \\
\hline C6 & 0.030 & 3 & 0.091 & 5 & 0.152 \\
\hline $\mathrm{C} 7$ & 0.027 & 7 & 0.187 & 6 & 0.160 \\
\hline $\mathrm{C} 8$ & 0.025 & 27 & 0.665 & 30 & 0.738 \\
\hline $\mathrm{C} 9$ & 0.017 & 10 & 0.168 & 14 & 0.235 \\
\hline \multicolumn{6}{|l|}{ B3 } \\
\hline $\mathrm{C} 10$ & 0.151 & 25 & 3.767 & 33 & 4.972 \\
\hline
\end{tabular}

\section{USE AHP MODEL TO EVALUATE THE SPECIFIC BPMS PRODUCTS}

We selected two leading software vendors' BPMS products in China for our comparison. All the indices in this AHP model are used and scored to evaluate the two softwares. The result is shown in Table 3 .

\section{RESULTS AND DISCUSSION}

After processing the data from experts' scored results, when considering user flexibility, the weights of usabilityreliability and portability-maintainability are relatively higher, i.e. respectively 0.418 and 0.403 , and the weight of functionality is only 0.179 . For users, the functions provided by systems differ very slightly. No matter what the process design is, or whether the process is optimized or monitored, all BPMSs more or less have these same features. In general, almost all the products can be used to satisfy the business and user needs. On the contrary, on the premise of functional process rarely determining users' attitude, the portability, maintainability, usability and reliability of the system can have huge impact on users. The applicability of the product's hardware and software and the simplicity and stability of use, have become important factors which can determine the user flexibility to a BPMS. This conclusion can be found in the comparison table of the two products.

\section{SUMMARY}

For BPMS users, a system's usability - reliability, and portability - maintainability are very important, while functionality lags behind. This provides the direction for BPMS's improvement and optimization. Even though it is a BPMS, yet it is required to have the basic process management functions and the ability to improve continuously. Many software vendors, currently aspire a powerful and perfect functionality in order to make the product seems perfect, but ignore the users' feelings when operating the systems. This is the root cause of many products failure and also the reason behind the rapid growth of some enterprises such as Apple who pays attention to the user experience. BPMS is flexible. It should be able to adapt to the changes from both external and internal business environment, in order to meet the needs of users in different conditions. So, the BPMS manufacturers must have a look at the user's view to think about system flexibility. They should also pay more attention to the system's port- 
ability, maintainability, usability and reliability that can make users even more satisfied.

\section{CONFLICT OF INTEREST}

The authors confirm that this article content has no conflict of interest.

\section{ACKNOWLEDGEMENTS}

This article is supported by "the Fundamental Research Funds for the Central Universities (NO. JGTD2014-01)".

\section{REFERENCES}

P. Ravesteijn and M. Zoet, "A BPM-Systems Architecture That Supports Dynamic and Collaborative Processes," Journal of International Technology \& Information Management, vol. 19, 2010.

[2] M. Shariati, F. Bahmani, and F. Shams, "Enterprise information security, a review of architectures and frameworks from intero- perability perspective," Procedia Computer Science, vol. 3, pp. 537-543, 2011.

[3] J. Gebauer and F. Schober, "Information system flexibility and the cost efficiency of business processes," Journal - Association for Information Systems, vol. 7, pp. 122-147, 2006.

[4] S. R. Koster, "An evaluation method for Business Process Management products," 2009.

[5] N. Russell, A. H. M. T. Hofstede, W. M. P. V. D. Aalst, and N. Mulyar, "Workflow ControlFlow Patterns: A Revised View," 2006.

[6] P. Wohed, N. Russell, A. H. M. ter Hofstede, B. Andersson, and W. M. P. van der Aalst, "Patterns-based evaluation of open source BPM systems: The cases of jBPM, OpenWFE, and Enhydra Shark," Information and Software Technology, vol. 51, pp. 1187$1216,8 / / 2009$.

[7] C. Cho and S. Lee, "A study on process evaluation and selection model for business process management," Expert Systems with Applications, vol. 38, pp. 6339-6350, 5// 2011.

(C) Wang et al.; Licensee Bentham Open.

This is an open access articles licensed under the terms of the Creative Commons Attribution-Non-Commercial 4.0 International Public License (CC BY-NC 4.0) (https://creativecommons.org/licenses/by-nc/4.0/legalcode), which permits unrestricted, non-commercial use, distribution and reproduction in any medium, provided that the work is properly cited. 